\title{
Deletion patterns of Duchenne and Becker muscular dystrophies in Greece
}

\author{
Lina Florentin, Ariadni Mavrou, Kiriaki Kekou, Catherine Metaxotou
}

\begin{abstract}
We present molecular data from 90 Greek boys with Duchenne or Becker muscular dystrophy using cDNA analysis or multiplex PCR or both. Deletions were detected in $63.3 \%$ of patients and were mainly clustered in two areas of the gene, one in the $3^{\prime}$ and one in the $5^{\prime}$ end of the gene (exons 3-19 and 44-53). Almost 17\% of deletion breakpoints lay in intron 44 while $29 \%$ of deletions have a breakpoint in intron 50. Thus the distribution of deletions in our DMD/BMD patients differs from that previously reported. Furthermore a $1: 4.35$ proximal:distal ratio was observed in familial cases and a $1: 2 \cdot 45$ ratio in isolated ones.
\end{abstract}

(f Med Genet 1994;32:48-51)

Southern blot analysis using cDNA probes and multiplex PCR reactions have shown that 65 $70 \%$ of DMD or BMD patients have deletions ${ }^{1-4}$ or duplications ${ }^{5}$ of one or more exons of the gene. In the remaining $35 \%$, the disease is assumed to result from point mutations. ${ }^{6}$ The percentage of detectable deletions in DMD/ BMD patients is similar for all the populations studied so far, with the exception of an Israeli study, where the reported incidence is very low $(39 \%){ }^{7}$

Deletions in the dystrophin gene are preferentially clustered in two areas, one in the $5^{\prime}$ end, between exons 3 to 7 , and one in the central to $3^{\prime}$ end with the majority of breakpoints in intron $44 .{ }^{18}$ Thus with the use of multiplex PCR for the most commonly deleted exons, it is possible to detect $98 \%$ of the deletions detected with cDNA probes. ${ }^{89}$

In the present study, we estimated the frequency and extent of deletions in 90 Greek $\mathrm{DMD} / \mathrm{BMD}$ boys using CDNA analysis and multiplex PCR analysis and compared the map of intragenic deletions and breakpoint "hot spots" detected in the Greek population with those of other populations. It is obvious that the experience obtained from this study greatly facilitates diagnosis and prenatal testing for the muscular dystrophies in Greece.

\section{Materials and methods}

This study performed for the first time in Greece included 90 boys, 74 with Duchenne and 16 with Becker muscular dystrophy. The diagnosis and classification of the patients was based on the classic clinical criteria, age of onset, CK values, electromyography (EMG), and muscle biopsy.

The first 55 patients were studied both with cDNA $^{14}$ probes and multiplex PCR for the simultaneous amplification of 18 exons of the gene $^{8}$ and the results have been previously reported. ${ }^{10}$ The remaining patients were studied with multiplex PCR and only when a deletion was not detected were they studied with the use of sets of primers for Ca1A, Cf56a, J66, and MP1P (Mountford et al, unpublished data ${ }^{11}$ and subsequently with cDNA probes.

Microsatellite repeats STR44 and STR50 were amplified ${ }^{12}$ in patients with a deletion end point in the respective intron.

\section{Results}

Deletions were detected in $63.3 \%$ of the patients, were heterogeneous in size, and were mainly clustered around exons 44-53 and 3-19 (figure). Specifically, in $48.8 \%$ of the patients $(75.8 \%$ of detectable deletions) deletions were detected primarily at the $3^{\prime}$ end of the gene and between exons 44-53. Ten patients $(17 \cdot 2 \%)$ had one deletion end point between exons 44 and 45 . Their DNA was further screened with microsatellite repeat STR44 which lies in intron 44 . It was found that STR44 was preserved in all nine deletions starting in intron 44 but was removed in the one deletion terminating in intron 44 . Seventeen deletions $(29.3 \%)$ had at least one end point between exons 50 and 51 . Screening with microsatellite repeat STR50 showed that of the 14 patients with a deletion ending at exon 50 , STR 50 was present in 13 of them ( $95 \%$ of these deletions stop before this marker). Furthermore STR50 was absent from three patients with a deletion of exon 51 . Almost $12 \%$ of deletions involved exons 48 to 50 . Only one deletion extended as far as exon 60 (figure).

In $15.5 \%$ of the patients $(24.2 \%$ of detectable mutations) mutations were detected at the $5^{\prime}$ end of the gene and were mainly clustered around exons 3-19. Seven of the deletions (12\% of deletions) had an end point possibly in intron 2 , while no patient had a deletion of the promoter or the first two exons of the gene. Only one deletion extended from exons 24 to 34 , and was detected first with $\mathrm{Ca} 1 \mathrm{a}$ and secondly with the use of cDNAs 4-5a and $5 \mathrm{~b}-7$.

A discontinuous deletion was identified with cDNA analysis, in which exons 19-21 and 26-29 were missing, while exons 22-25 were detected as a $20 \mathrm{~kb}$ HindIII restriction fragment. Further investigation of this patient's DNA (digestion with several restriction en- 


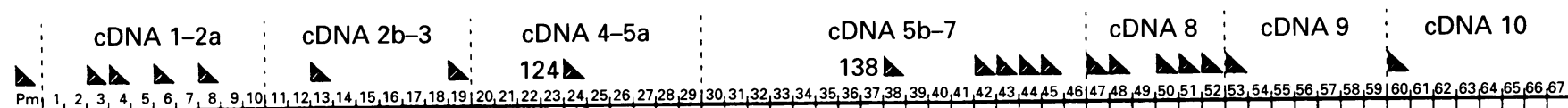

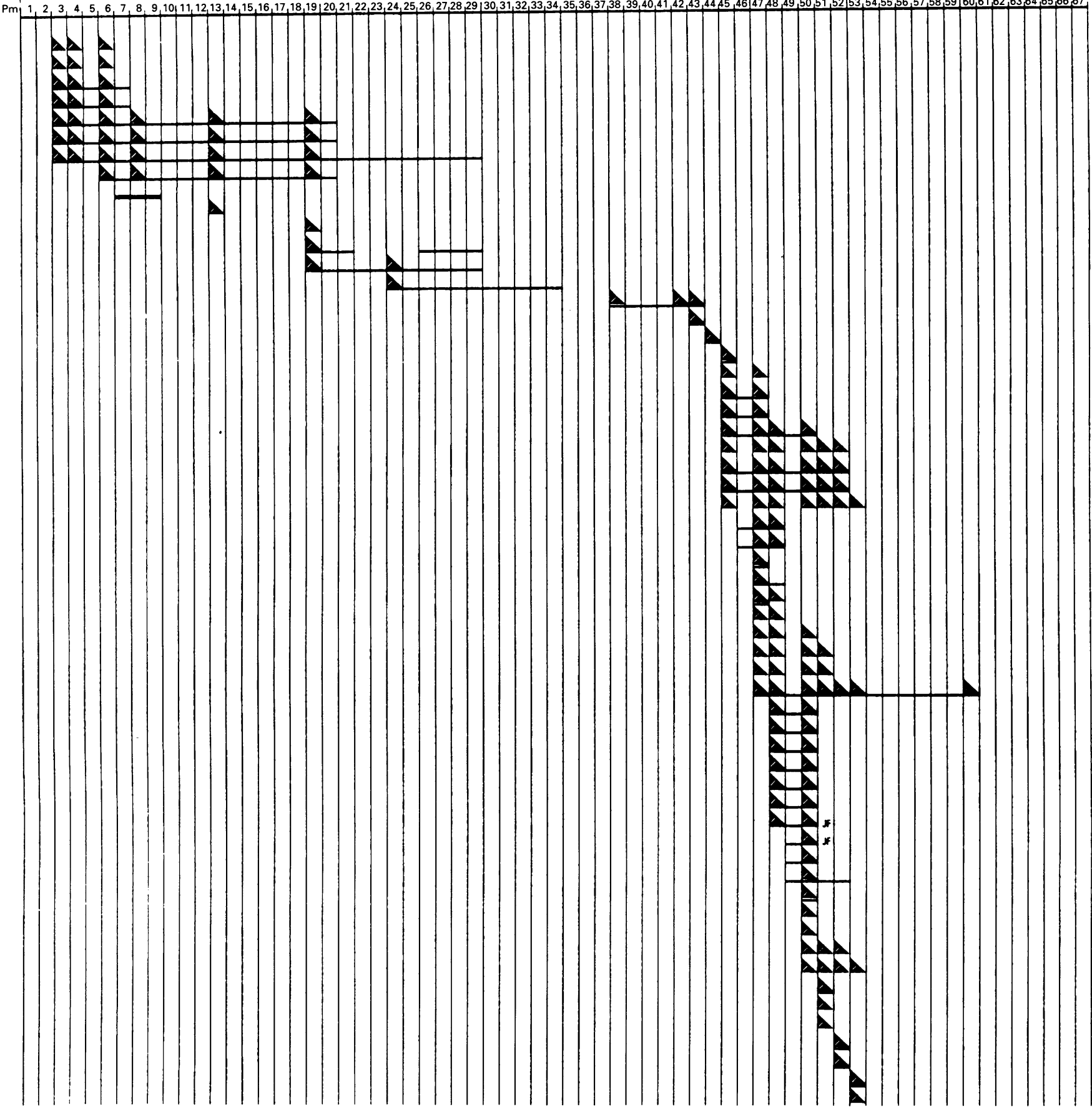

Position and extent of deletions detected in Greek DMD/BMD patients using cDNA analysis or multiplex PCR or both for 18 exons of the dystrophin gene. Thin lines: deletions detected using $c D N A$; bold line: duplication detected with cDNA; triangles: deletions detected using PCR; $\mathcal{F} F$; junction fragment.

zymes and comparison with normal male controls) excluded the possibility that this could be a junction fragment of exactly the same size as the $20 \mathrm{~kb}$ fragment.

A duplication was detected in our sample shown with cDNA 1-2a for exons 7-9. The duplication was identified by comparing the intensities of different bands in the same track and in the tracks of the two adjacent samples. No systematic dosage analysis was undertaken in order to detect the actual percentage in our patients.

In one patient a deletion of exon 47 was detected with both techniques but multiplex PCR detected in addition to this a deletion of exon 48 and further investigation is considered. Reduction of the annealing temperature did not succeed in amplifying exon 48. In another patient cDNA analysis showed a deletion of exons 48-50, plus an additional junction fragment. PCR did not show a deletion of exon 48 , suggesting a deletion of exons $49-50$, with exon 48 being present in the junction fragment.

Of the 16 boys with Becker muscular dystrophy, deletions were detected in eight cases. Three patients had deletions of exons 45-47, 
No of Duchenne familial and isolated cases with a detectable deletion in the $3^{\prime}$ and $5^{\prime}$ end of the dystrophin gene

\begin{tabular}{lcc}
\hline & No of $5^{\prime}$ end deletions (\%) & No of $3^{\prime}$ end deletions (\%) \\
\hline $\begin{array}{l}\text { No of familial cases }=11 \\
\text { Ratio: } 1 \text { proximal:4.35 distal }\end{array}$ & $2(18 \cdot 8 \%)$ & $9(81 \cdot 8 \%)$ \\
$\begin{array}{l}\text { No of isolated cases }=38 \\
\text { Ratio: } 1 \text { proximal:2.45 distal }\end{array}$ & $11(28.94 \%)$ & $27(71 \cdot 06 \%)$ \\
\hline
\end{tabular}

and the other five had deletions of exons 38-43, 45-53, 47-48, 50-52, and 50-53. All BMD patients seemed to have a deletion in the $3^{\prime}$ end of the gene.

In our sample there were 65 isolated and 25 familial cases and the incidence of Duchenne or Becker patients was the same in both groups. Deletions were detected in $66.2 \%$ of DMD patients and $50 \%$ of BMD patients. More deletions were detected among sporadic cases $(67 \cdot 6 \%)$ than familial $(56 \%)$ ones. Specifically there is a $17 \%$ increase in deletions detected among isolated cases of DMD rather than among familial cases, while in Becker families there is a $15 \%$ increase of detectable deletions among familial cases. Moreover, we have observed a $1: 4.35$ proximal:distal ratio in $\mathrm{Du}-$ chenne familial cases as opposed to a 1:2.45 ratio in isolated cases (table).

\section{Discussion}

The percentage of deletions $(63 \cdot 3 \%)$ detected in our $\mathrm{DMD} / \mathrm{BMD}$ patients is in agreement with those reported for other populations ${ }^{1241314}$ with the exception of the Israeli study. ${ }^{7}$ The distribution of the observed deletions agrees with the reported ones. We have shown that $17 \cdot 2 \%$ of detectable deletions had a breakpoint in intron 44 supporting previous reports of a breakpoint "hot spot" in this intron. ${ }^{1516}$ STR44 segregated preferentially with exon 44 , so the breakpoint maps distal to this marker. ${ }^{17} \mathrm{Al}-$ though our results support that intron 44 is a breakpoint "hot spot", the percentage of deletions detected in this area $(17 \cdot 2 \%)$ is lower than the $32 \%$ published. ${ }^{116}$ On the other hand a higher percentage $(29.3 \%)$ of our patients had at least an end point in intron 50 and STR50 segregated preferentially with exon 51 . Thus in our population the major deletion breakpoint "hot spot" is located proximal to this marker in intron 50 rather than in intron 44. In contrast to other reports, ${ }^{18}$ deletions of the promoter or the first two exons of the gene were not observed in our DMD/BMD patients. Almost $12 \%$ of detectable deletions had a breakpoint in intron 2 which could be regarded as a minor deletion "hot spot" of the $5^{\prime}$ end of the gene, in agreement with previous reports. ${ }^{18}$ The observed differences in the distribution of deletions in our sample coud be explained by the hypothesis that intronic sequences could accumulate differences in different populations $^{18}$ and that the so called "local DNA environment" might play a role in the creation of deletions and mutations. ${ }^{1920}$

The discontinuous deletion detected may be the result of a complex rearrangement within the gene in that particular region. Very few discontinuous deletions have been reported so far. ${ }^{2122}$

A small increase was noted in the percentage of detectable deletions in isolated rather than familial cases but not to the extent reported by others. ${ }^{22}$ However, while this is true for the Duchenne cases the opposite was observed for the Becker cases and this is in contradiction to the above report. Moreover, our data do not support the hypothesis that proximal and distal deletions occur equally in familial cases ${ }^{23}$ and we observed that in isolated cases the ratio is much higher than the reported one.

The authors wish to thank Professors M A Ferguson-Smith, $M$ Connor, and $M$ Bobrow and their scientific teams for their support during the establishment of this laboratory. They are also indebted to Dr Steven Abbs for his invaluable help, advice, and support throughout this study. The authors are grateful to all families and clinicians for providing them with blood samples and information on patients. This study was supported by the and information on patien
Greek Ministry of Health.

1 Koenig M, Hoffman EP, Bertelson CJ, Monaco AP, Feener C, Kunkel LM. Complete cloning of the Duchenne musC, Kunkel LM. Complete cloning of the Duchenne muscular dystrophy (DMD) cDNA gene in

2 Den Dunnen JT, Bakker E, Klein Breteler EG, Pearson PL, van Ommen GJB. Direct detection of more than $50 \%$ of the Duchenne muscular dystrophy mutations by pulse field inversion gels. Nature 1987;329:640-2.

3 Forrest SM, Cross GS, Thomas NST, et al. Effective strategy for prenatal prediction of Duchenne and Becker muscular dystrophy. Lancet 1987;ii:1294-7.

4 Darras BT, Koenig M, Kunkel LM, Francke U. Direct method for prenatal diagnosis and carrier detection in Duchenne/Becker muscular dystrophy using the entire dystrophin cDNA. Am $\mathcal{F}$ Med Genet 1988;29:713-26.

$5 \mathrm{Hu}$ X, Burghes AHM, Rau PN, Thompson MW, Murphy EG, Worton RG. Partial gene duplication in Duchenne and Becker muscular dystrophies. $\mathcal{F}$ Med Genet 1988;25: 369-76.

6 Roberts RG, Barby TFM, Manners E, Bobrow M, Bentley DR. Direct detection of dystrophin gene rearrangements by analysis of dystrophin mRNA in peripheral blood lymphocytes. Am ₹ Hum Genet 1991;49:298-310.

7 Shomrat R, Gluck E, Legum C, Shiloh Y. The proportion of gene deletions detected by CDNA probes and PCR is of gene deletions deced by relatively low in Israeli patients with Duchenne and Becker 204.

8 Abbs S, Yau SC, Clark S, Mathew CG, Bobrow M. A convenient multiplex PCR system for the detection of dystrophin gene deletions: a comparative analysis with cDNA hybridisation shows mistyping with both methods. M Med Genet 1991;28:304-11.

9 Chamberlain JS, Chamberlain JR, Fenwick RG, et al. Diagnosis of Duchenne's and Becker's muscular dystrophy by nosis of Duchenne's and Becker's muscular dystrophy by polymerase chain rea

10 Florentin L, Mavrou A, Metaxotou C. Deletions detected in Greek DMD/BMD patients using CDNA analysis and multiplex PCR: a comparative study. European Society of Human Genetics, 24th Annual Meeting, 1992;971:71.

11 Roberts RG, Montandon AJ, Bobrow M, Bentley DR. Detection of novel genetic markers by mismatch analysis. Nucleic Acids Res 1989;17:5961-71.

12 Clemens PR, Fenwick RG, Chamberlain JS, et al. Linkage analysis for Duchenne and Becker muscular dystrophies using dinucleotide repeat polymorphisms. Am $\mathcal{f} \mathrm{Hum}$ Genet 1991;49:951-61.

13 Darras BT, Blattner P, Harper JF, Spiro AJ, Alter S, Franche $U$. Intragenic deletions in 21 Duchenne muscular dystrophy (DMD)/Becker muscular dystrophy (BMD) families studied with the dystrophin cDNA: location of breakpoints on Hind III and Bgl II exon-containing fragment maps, meiotic and mitotic origin of mutations. $\mathrm{Am}$ f Hum Genet 1988;43:620-9.

14 Cooke A, Lanyon WG, Wilcox DE, et al. Analysis of Scottish Duchenne and Becker muscular dystrophy families with Duchenne and Becker muscular dystrophy families with

15 Wapenaar MC, Kievits T, Hart KA, et al. A deletion hot spot in the Duchenne muscular dystrophy gene. Genomics 1988;2:101-8.

16 Den Dunnen JT, Grootsholten PM, Bakker E, et al. Topography of the Duchenne muscular dystrophy (DMD) gene. FIGE and cDNA analysis of 194 cases reveals 115 deletions ar $835-47$.

17 Oudet C, Hanauer A, Clemens P, Caskey T, Mandel J-L. Two hot spots of recombination in the DMD gene correlate with the deletion prone regions. Hum Molec Genet 1992;1:599-603.

18 Danieli GA, Mioni F, Muller CR, Vitiello L, Mostacciulo ML, Grimm T. Patterns of deletions of the dystrophin ML, Grimm T. Patterns of deletions of the dystrophin 91:342-6. 
19 Krawczak M, Cooper DN. Gene deletions causing human genetic disease: mechanisms of mutagenesis and the role of the local DNA sequence environment. Hum Genet 1991; 86:425-41.

20 Cooper DN, Krawczak M. Mechanisms of insertional mutagenesis in human genes causing genetic disease. Hum Genet 1991;87:409-15.

21 Read AP, Mountford RC, Forrest SM, Kenwrick SJ, Davies KE, Harris $R$. Patterns of exon deletions in Duchenne and
Becker muscular dystrophies. Hum Genet 1988;80:152-6. 22 Passos-Bueno MR, Rapaport D, Love D, et al. Screening of deletions in the dystrophin gene with the cDNA probes Cf23a, Cf56a, and Cf115. F Med Genet 1990;27:145-50. 23 Passos-Bueno MR, Bakker E, Kneppers ALJ, et al. Different mosaicism frequencies for proximal and distal Duchenne muscular dystrophy (DMD) mutations indicate difference in etiology and recurrence risk. Am f Hum Genet 1992; 